\title{
FORMAS E QUANTIDADES DE CARBONO EM LIXIVIADOS DE LATOSSOLOS VERMELHOS SOB INFLUÊNCIA DE CALCÁRIO E FÓSFORO ${ }^{(1)}$
}

\author{
Antônio Claret de Oliveira Júnior ${ }^{(2)}$, Carlos Alberto Silva ${ }^{(3)}$, Nilton \\ Curi $^{(3)}$, José Maria de Lima ${ }^{(3)}$ \& Otacílio José Passos Rangel ${ }^{(4)}$
}

\begin{abstract}
RESUMO
No solo, a concentração e as formas de carbono solúvel em água (CSA) são reguladas por atributos como qualidade e teor de matéria orgânica, acidez, disponibilidade de nutrientes, mineralogia e fatores ligados à comunidade microbiana. Este estudo teve por objetivo avaliar as quantidades e formas de carbono (C) em lixiviados de Latossolos com diferentes teores de Fe sob influência de calcário e, ou, P. Em áreas da Bacia do Rio das Mortes (MG), amostras de Latossolos Vermelhos (mesoférrico (LV1) e hipoférrico (LV2)) foram coletadas e submetidas aos seguintes tratamentos: 1- controle; 2 - $\mathrm{P}$ (50 \% da capacidade máxima de adsorção de P); 3- calcário (V= 85 \%); 4- Ca + P (doses dos tratamentos 3 e 4). Foi adotado o delineamento experimental inteiramente casualizado, com três repetições por tratamento. As quantidades e a distribuição de massa molar do CSA foram avaliadas em dez coletas consecutivas de lixiviados. Além disso, foram avaliados os teores e tipos de ácidos orgânicos de baixa massa molar (AOBMM) associados ao CSA. Em ambos os solos, as quantidades de CSA aumentaram na seguinte ordem: controle $\leq$ calcário $<\mathrm{P}<\mathrm{Ca}+\mathrm{P}$. O CSA foi maior no LV2, em relação ao LV1. A massa molar média das frações de CSA no efluente aumentou com o tempo, para os tratamentos com $\mathrm{Ca}+\mathrm{P}$. As maiores massas molares foram observadas para o LV2, nos tratamentos com $\mathrm{P}$ e Ca + P. Em geral, o LV1 perdeu mais C na forma de AOBMM do que o LV2.
\end{abstract}

Termos para indexação: ácido orgânico, ácido fúlvico, massa molar, carbono solúvel em água, solos tropicais, óxidos de ferro.

\footnotetext{
(1) Parte da Tese de Doutorado do primeiro autor, apresentada ao Curso de Pós-Graduação em Ciência do Solo da Universidade Federal de Lavras - UFLA. Projeto financiado pela FAPEMIG. Recebido para publicação março de 2007 e aprovado em fevereiro de 2008.

${ }^{(2)}$ Doutor em Ciência do Solo. Av. Afonso Pena 2403, CEP 70002-073 Campo Grande (MS). E-mail: antoniocoliveirajr@yahoo.com.br

(3) Professor do Departamento de Ciência do Solo, UFLA. E-mails: csilva@ufla.br; niltcuri@ufla.br; jmlima@ufla.br

${ }^{(4)}$ Doutor em Solos e Nutrição de Plantas. E-mail: otaciliorangel@yahoo.com.br
} 


\title{
SUMMARY: CARBON FORMS AND QUANTITIES IN LEACHATES FROM OXISOLS UNDER INFLUENCE OF LIME AND PHOSPHORUS
}

\begin{abstract}
In the soil, forms and content of water-soluble carbon (WSC) are influenced by factors such as organic matter quality and content, soil acidity, nutrient availability, mineralogy, and aspects related to the microbial community. This study aimed to evaluate forms and quantities of carbon $(C)$ in leachates from Latosols (Oxisols) with different Fe contents, amended with lime and/or phosphorus. Samples of mesoferric Red Latosol (LV1) and hypoferric Red Latosol (LV2) were collected in the Rio das Mortes wathershed, state of Minas Gerais, Brazil, and treated as follow: 1- control, 2- phosphorus (50\% of maximum phosphorus adsorption capacity), 3-liming ( $V=85 \%)$, 4- liming+phosphorus (doses equivalent to treatments 2 and 3). The experimental design was completely randomized, with three replications. Quantities of WSC and molar mass distribution were measured in ten consecutive leachate samples. Contents and types of low molar mass organic acids, associated with WSC, were also measured. In both soils, the quantities of water-soluble carbon increased in the following order: control $\leq$ liming $<$ phosphorus $<$ liming + phosphorus. Water-soluble carbon in the LV2 was higher than in the LV1. Liming + phosphorus increased the average molecular mass of the WSC fractions in the leachates over time. The highest masses were found when the LV2 was amended with phosphorus or liming + phosphorus. More $C$ in the organic acid form was leached from the LV1 than from the LV2.
\end{abstract}

Index terms: organic acid, fulvic acid, molar mass, water-soluble carbon, tropical soils, iron oxides.

\section{INTRODUÇÃO}

No sistema solo-planta, o $\mathrm{C}$ pode ser perdido por volatilização, dependendo do evolvimento de $\mathrm{CO}_{2}$ e $\mathrm{CH}_{4}$ para a atmosfera, por erosão, arrastado junto com o sedimento, e por lixiviação, junto com a água que percola no solo (Karlik, 1995). As perdas de C por lixiviação são, de fato, reduzidas, uma vez que o C solúvel em água (CSA) contribui somente para pequena fração da matéria orgânica do solo (MOS), mas podem ser significativas ao longo do tempo, quando se consideram as quantidades acumuladas de C perdidas e a velocidade em que o C da solução é reposto pela fase sólida, em alguns sistemas de manejo. O CSA pode ser definido como moléculas orgânicas de diferentes tamanhos e estruturas que passam em membrana de filtragem de poro de $0,45 \mu \mathrm{m}$ (Kalbitz et al., 2000), englobando ácidos fúlvicos, polissacarídeos, ácidos gordurosos de cadeia longa, ésteres (Stevenson, 1994), ácidos orgânicos e aminoácidos (Herbert \& Bertsch, 1995).

Funcionalmente, o CSA caracteriza-se como um dos principais fatores de formação do solo (Dawson et al., 1978), por atuar sobre a intemperização de minerais (Raulund-Rasmussen et al., 1998). Essa forma de $\mathrm{C}$ regula o transporte de poluentes e de nutrientes no solo, podendo atuar também como complexante de metais pesados, amenizando potenciais efeitos tóxicos às plantas (Stevenson, 1994). As fontes potenciais de CSA são a serrapilheira e os compartimentos da MOS (Kalbitz et al., 2000), como, por exemplo, a biomassa microbiana e as raízes. $\mathrm{O}$ balanço estabelecido entre o $\mathrm{C}$ associado a esses compartimentos e aquele na solução do solo é regulado por processos químicos e bioquímicos, sendo que os fatores bióticos e abióticos determinam sua intensidade (Kalbitz et al., 2000). Dentre esses últimos, destacamse: $\mathrm{pH}$, teor de matéria orgânica, concentração de ânions, adubação nitrogenada, práticas de preparo e de drenagem, composição mineralógica, etc. (Chantigny, 2003).

Em solos corrigidos quimicamente, há maior concentração de $\mathrm{C}$ na solução, acréscimo este associado à maior solubilidade da MOS (Erich \& Trusty, 1997), ao aumento da atividade microbiana e de produção de compostos mais solúveis (Guggenberger et al., 1994), além da substituição de CSA adsorvido à fase sólida por ânions mobilizados (troca de ligantes) após a adição de calcário no solo (Kalbitz et al., 2000). Por outro lado, o consumo de $\mathrm{C}$ dissolvido em água pela microbiota (Andersson, 1999) e a floculação ou adsorção de $\mathrm{C}$ em pontes de cátions formadas em razão da alto teor de Ca no solo podem contribuir para as perdas de $\mathrm{C}$ via solução em solos onde a acidez é corrigida. Portanto, em solos minerais não corrigidos, as baixas concentrações de $\mathrm{C}$ solúvel são devidas mais aos fenômenos de adsorção que aos de biodegradação (Miranda et al., 2006).

Apesar de o $\mathrm{C}$ orgânico dissolvido em água representar somente pequena parte do C lábil do solo (van Hees et al., 2005), estudos desenvolvidos em vasos e lisímetros (Karlik, 1995) mostraram que a perda de C por lixiviação pode ser até $53 \%$ maior em solos tratados com carbonato de Ca. Isso evidencia que, 
além de causar diminuição nos teores de $\mathrm{C}$ do solo, a correção da acidez altera os modelos de migração e de ciclagem da matéria orgânica. Silva et al. (2000) observaram que a aplicação de calcário, por favorecer a decomposição da matéria orgânica, aumentou o teor de C-ácido fúlvico no solo. Essas moléculas alifáticas, como apresentam maior quantidade de radicais carboxílicos do que outros grupos de substâncias húmicas, são mais reativas no solo, mostram maior solubilidade e menor massa molar e podem, por conseguinte, ser solvatadas e perdidas mais facilmente por lixiviação (Stevenson, 1994). Marschner \& Wilczynsky (1991) observaram que a aplicação de calcário em solos sob floresta promoveu aumento da concentração de ácidos fúlvicos nas camadas mais profundas do solo, com diminuição da concentração de ácidos húmicos, evidenciando maior mobilidade das substâncias húmicas de menor massa molar.

Dentro do grupo de moléculas reativas no solo, além dos ácidos fúlvicos, destacam-se os ácidos orgânicos de baixa massa molar (AOBMM). Apesar de estarem presentes em baixa concentração na solução, aproximadamente $3 \%$ do CSA (van Hees et al., 1999), desempenham inúmeras funções no solo, sobretudo na rizosfera, tais como: complexação de metais (Fox \& Comerford, 1990), aumento da disponibilidade de $\mathrm{P}$ (Andrade et al., 2003), maior mobilidade de cátions complexados no perfil, etc. Os AOBMM, apesar de sua baixa persistência no solo, são mantidos em teores relativamente constantes, evidenciando alta reposição na solução do solo, que ocorre por meio da produção de exsudatos por raízes e microrganismos, além de produtos de decomposição da matéria orgânica e de resíduos orgânicos, muito embora seja difícil separar a origem dessas fontes no solo (van Hees et al., 2005) e identificar essas moléculas em solos tropicais (Miyazawa \& Pavan, 1992).

Em geral, os fatores que afetam a atividade microbiana exercem influência sobre as concentrações de CSA e de C-AOBMM, com destaque para as aplicações de calcário (Roth \& Pavan, 1991) e P (Myers \& Thien, 1991), visto que estas aplicações aumentam o pH do solo. O efeito da aplicação de $\mathrm{P}$ sobre o pH é atribuído a ligações covalentes do fosfato aos óxidos de $\mathrm{Fe}$ e Al, formando complexos de esfera interna, cujas ligações liberam radicais hidroxílicos da fase sólida para a solução, aumentando o $\mathrm{pH}$ do solo (Myers \& Thien, 1991). Além disso, os óxidos (termo inclusivo para óxidos, oxidróxidos e hidróxidos) de $\mathrm{Fe}$ do solo restringem os teores de matéria orgânica dissolvida, em virtude da adsorção dos compostos orgânicos às superfícies daqueles minerais (Kalbitz et al., 2000), conferindo proteção à matéria orgânica, por restringir o acesso dos microrganismos às moléculas orgânicas no interior dos agregados (Golchin et al., 1994) e adsorvidas aos colóides inorgânicos.

A Bacia do Rio das Mortes (BRM), localizada em Minas Gerais, engloba 26 municípios, que se destacam pela produção agrícola, notadamente de batata na sua porção leste. Nessa área, predominam Latossolos e Cambissolos de baixa fertilidade natural, sendo a correção da acidez e a adição de $\mathrm{P}$ práticas agronômicas freqüentes (Curi et al., 1994). Essas práticas exercem forte influência sobre a comunidade microbiana e sobre a dinâmica de diferentes compartimentos de $\mathrm{C}$, tendo implicações importantes sobre a sustentabilidade dos agroecossistemas locais, uma vez que a matéria orgânica é o principal reservatório de cargas e nutrientes desses solos.

Na BRM, a correção da acidez do solo é realizada em praticamente todas as áreas cultivadas e as doses de fosfato variam entre as culturas. Em áreas de produção de batata, tem sido comum a aplicação, em cada ciclo da cultura, de doses entre 2.000 e $2.500 \mathrm{~kg} \mathrm{ha}^{-1}$ da fórmula 4-16-8, o que, em menos de 10 anos, pode atingir metade da capacidade máxima de adsorção de $\mathrm{P}$ de grande parte dos solos agrícolas da região. Muitas vezes, essas quantidades de P são aplicadas sem se avaliarem o requerimento nutricional da cultura e a capacidade do solo em suprir esse nutriente. Isso pode resultar em contaminação ambiental, além do aumento do custo de produção, pela aplicação de doses de $\mathrm{P}$ que proporcionam baixo retorno econômico. Por se tratarem de solos com diversas deficiências nutricionais, tanto o uso de calcário quanto o de fosfato são indispensáveis para a produção das culturas. No entanto, essas práticas podem interferir na ciclagem e dinâmica de frações da matéria orgânica do solo, como, por exemplo, o CSA, em suas diversas formas. Assim, a calagem, isoladamente, ou em conjunto com adubação fosfatada, pode elevar a lixiviação de $\mathrm{C}$, em concentrações acima do normalmente encontrado em condições naturais. Isso se deve, provavelmente, ao fato de a calagem e a adubação fosfatada diminuírem o ponto isoelétrico do solo e favorecerem a decomposição de compostos orgânicos, a capacidade de troca de cátions líquida do solo e a dispersibilidade da argila (Lima et al., 2000). Além disso, o fosfato desloca ânions orgânicos da superfície coloidal para a solução do solo, favorecendo sua lixiviação para as camadas mais profundas, onde a capacidade de retenção é menor.

No Brasil, são escassos os estudos (Azevedo et al., 1996; Miranda et al., 2006) que consideram o fluxo vertical de $\mathrm{C}$, mas estes demonstram a ocorrência de perdas de CSA do sistema solo-planta de acordo com o manejo. Nesse sentido, estudos da composição de materiais da solução do solo podem ser úteis para investigar a influência das atividades antrópicas sobre a qualidade do solo (Miranda et al., 2006), como, por exemplo, os efeitos de práticas de correção da fertilidade em solos agrícolas da BRM.

Este estudo teve por objetivo avaliar os efeitos da calagem, em combinação ou não com aplicação de $\mathrm{P}$, sobre as quantidades e formas de $\mathrm{C}$ solúvel em água, presentes em lixiviados de Latossolos Vermelhos (mesoférrico e hipoférrico). 


\section{MATERIAL E MÉTODOS}

O experimento foi realizado em lisímetros do Laboratório de Conservação do Solo e da Água do Departamento de Ciência do Solo da Universidade Federal de Lavras, em amostras representativas de solos agrícolas da Bacia do Rio das Mortes (BRM). Para tanto, foram utilizadas amostras de dois Latossolos Vermelhos, sendo um mesoférrico (LV1) e outro hipoférrico (LV2), coletadas na profundidade de 0-20 cm. Após o destorroamento, o material dos solos foi seco ao ar, peneirado (malha de $4 \mathrm{~mm}$ ) e caracterizado física e quimicamente, conforme Embrapa (1997) (Quadro 1).

As amostras foram incubadas para se obter os seguintes tratamentos: controle, $\mathrm{P}$, calcário $(\mathrm{Ca})$ e $\mathrm{Ca}+\mathrm{P}$, com três repetições, perfazendo 24 parcelas experimentais, dispostas em delineamento experimental inteiramente casualizado. A dose de calcário foi suficiente para elevar a saturação por bases a $85 \%$, pelo uso de calcário dolomítico calcinado (PRNT $100 \%$, $35 \%$ de $\mathrm{CaO}$ e $14 \%$ de $\mathrm{MgO}$ ). Essa saturação por bases foi adotada com vistas em alcançar um $\mathrm{pH}$ de solo mais alto, pois não raro encontram-se solos agrícolas na BRM com $\mathrm{pH}$ acima do recomendado. Um exemplo são áreas de cultivo de batata com $\mathrm{pH}$ até 6,4 , quando um valor de 5,5 já seria suficiente. Além disso, pelo fato de se tratar de estudo em lisímetros, a grande desagregação do solo faz com que, comumente, a quantidade de calcário aplicada não eleve o $\mathrm{pH}$ tanto quanto elevaria em condições de campo. Assim, as doses de calcário aplicadas no LV1 e no LV2 foram equivalentes a 3,1 e 4,6 $\mathrm{Mg} \mathrm{ha}^{-1}$, respectivamente. Todos os solos foram incubados em contêineres de $1.000 \mathrm{~L}$ durante 35 dias, tempo suficiente para que os tratamentos que receberam calcário atingissem $\mathrm{pH}$ 6,4. Após esse período, os solos foram novamente secos ao ar, misturando-se as respectivas doses de $\mathrm{P}$, na forma de $\mathrm{KH}_{2} \mathrm{PO}_{4}$ próanálise, as quais foram estabelecidas visando atingir metade da capacidade máxima de adsorção de $\mathrm{P}$ (Nóbrega et al., 2005), equivalendo a $385 \mathrm{mg} \mathrm{kg}^{-1}$ para o LV1 e $500 \mathrm{mg} \mathrm{kg}^{-1}$ para o LV2. Vinte e oito litros e meio dessa mistura foram acondicionados em cada célula de lisímetro, onde permaneceram por mais 45 dias para incubação com fosfato. Durante o período de incubação, o teor de água das amostras foi mantido na capacidade de campo. Após esse período, mas antes do início das lixiviações, os solos foram novamente amostrados para análises químicas (Quadro 2). A bateria de lisímetros foi construída em aço inoxidável, com cada célula apresentando volume de $0,033 \mathrm{~m}^{3}$ $(0,32 \times 0,32 \times 0,32 \mathrm{~m})$.

Após o período de incubação com fosfato, foram iniciadas as aplicações de água, com o objetivo de promover fluxo hídrico nas colunas. A cada três dias foi aplicado 1,7 L de água deionizada por célula, correspondendo a uma lâmina de $17 \mathrm{~mm}$ por aplicação, num total de 10 aplicações. A lâmina de água foi baseada na média histórica de chuvas dos meses de outubro e novembro da estação climatológica de Barbacena-MG. Nos intervalos entre aplicações, a umidade do solo foi mantida próxima da capacidade de campo, por meio de pesagens comparativas de recipiente referência.

$\mathrm{O}$ volume de efluente foi medido a cada coleta, tomando-se uma alíquota filtrada $(0,45 \mu \mathrm{m})$, para determinação das concentrações de C orgânico solúvel em água (CSA), baseando-se em Mendonça \& Matos (2005). As quantidades de CSA foram obtidas relacionando-se os volumes dos efluentes as concentrações de CSA, em cada coleta.

As massas molares dos compostos orgânicos nos lixiviados foram determinadas por meio da cromatografia de exclusão por tamanho de alta eficiência (CETAE), detalhada em Silva et al. (2000). Dadas as limitações da técnica, pela proximidade das massas molares de várias das moléculas, somente foram determinadas as substâncias com massas molares maiores que 300 daltons.

Para identificar e quantificar os ácidos orgânicos de baixa massa molar (AOBMM), empregou-se cromatografia líquida de alta eficiência. As amostras dos lixiviados foram filtradas em membrana celulósica com $0,45 \mu \mathrm{m}$ de diâmetro para a injeção em coluna cromatográfica, modelo Supelcogel C- $610 \mathrm{H}$, $30 \times 7,8 \mathrm{~mm}$. Como padrões, foram utilizadas

Quadro 1. Atributos físicos e químicos dos Latossolos Vermelhos (mesoférrico - LV1 e hipoférrico - LV2), antes da aplicação dos tratamentos

\begin{tabular}{|c|c|c|c|c|c|c|c|c|c|c|c|c|}
\hline Solo & $\mathrm{pH}$ & Argila & Areia & $\mathrm{APw}>2 \mathrm{~mm}$ & $\mathbf{P}$ & P-rem & CMAP & $\mathrm{V}$ & COT & $\mathrm{Fe}_{2} \mathrm{O}_{3}$ & $\mathbf{K i}$ & $\mathbf{K r}$ \\
\hline & & 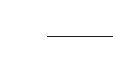 & — & - & 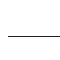 & $-\mathrm{mg} \mathrm{L}$ & ـ & 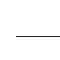 & - $\%$ & - & & \\
\hline LV1 & 5,6 & 48 & 35 & 99,4 & 1,2 & 16,4 & 769 & 52 & 3,0 & 15,1 & 1,1 & 0,8 \\
\hline LV2 & 4,8 & 54 & 36 & 97,4 & 0,9 & 10,5 & 1.000 & 14 & 2,0 & 7,7 & 0,6 & 0,5 \\
\hline
\end{tabular}

$\mathrm{pH}=\mathrm{pH}$ em água; $\mathrm{P}$ = fósforo (Mehlich-1); V = saturação por bases; COT = carbono orgânico total (Yeomans \& Bremner, 1988); $\mathrm{APw}>2 \mathrm{~mm}$ = agregados pré-umedecidos estáveis em água com diâmetro maior que $2 \mathrm{~mm} ; \mathrm{Fe}_{2} \mathrm{O}_{3}=\mathrm{Fe}$ total (ataque sulfúrico); P-rem $=\mathrm{P}$ remanescente (Alvarez V. et al., 2000); CMAP = capacidade máxima de adsorção de P. Relações moleculares: $\mathrm{Ki}^{=} \mathrm{SiO}{ }_{2} /$ $\mathrm{Al}_{2} \mathrm{O}_{3} ; \mathrm{Kr}=\mathrm{SiO}_{2} /\left(\mathrm{Al}_{2} \mathrm{O}_{3}+\mathrm{Fe}_{2} \mathrm{O}_{3}\right)$. 
Quadro 2. Propriedades químicas dos Latossolos Vermelhos (mesoférrico - LV1 e hipoférrico - LV2), após aplicação de calcário e, ou, fósforo, antes do início das lixiviações

\begin{tabular}{|c|c|c|c|c|c|c|c|c|}
\hline \multirow{2}{*}{ Atributo } & \multicolumn{2}{|c|}{ Controle } & \multicolumn{2}{|c|}{ Calcário } & \multicolumn{2}{|c|}{ Fósforo } & \multicolumn{2}{|c|}{ Calcário + fósforo } \\
\hline & LV1 & LV2 & LV1 & LV2 & LV1 & LV2 & LV1 & LV2 \\
\hline $\mathrm{pH}\left(\mathrm{H}_{2} \mathrm{O}\right)$ & 5,3 & 4,3 & 6,0 & 6,0 & 5,4 & 5,4 & 6,2 & 6,4 \\
\hline P-Mel (mg dm $\left.{ }^{-3}\right)$ & 1,3 & 1,0 & 1,9 & 0,9 & 51,2 & 54,6 & 48,8 & 46,3 \\
\hline P-Res $\left(\mathrm{mg} \mathrm{dm}^{-3}\right)$ & 3,3 & 1,0 & 3,2 & 2,8 & 133,3 & 155,2 & 115,3 & 168,8 \\
\hline $\mathrm{K}\left(\mathrm{mg} \mathrm{dm} \mathrm{m}^{-3}\right)$ & 88,3 & 20,3 & 52,0 & 31,2 & 274,7 & 135,6 & 107 & 287,3 \\
\hline $\mathrm{Ca}^{2+}\left(\mathrm{cmol}_{\mathrm{c}} \mathrm{dm}^{-3}\right)$ & 2,7 & 0,4 & 4,5 & 3,0 & 3,3 & 0,5 & 4,4 & 2,9 \\
\hline $\mathrm{Mg}^{2+}\left(\mathrm{cmol}_{\mathrm{c}} \mathrm{dm}^{-3}\right)$ & 1,3 & 0,1 & 1,9 & 1,4 & 1,2 & 0,2 & 2,3 & 1,5 \\
\hline $\mathrm{SB}\left(\mathrm{cmol}_{\mathrm{c}} \mathrm{dm}^{-3}\right)$ & 4,2 & 0,6 & 6,6 & 4,5 & 5,2 & 1,1 & 6,9 & 5,1 \\
\hline $\mathrm{t}\left(\mathrm{cmol}_{\mathrm{c}} \mathrm{dm}^{-3}\right)$ & 4,5 & 1,9 & 6,6 & 4,5 & 5,4 & 1,8 & 6,9 & 5,1 \\
\hline $\mathrm{T}\left(\mathrm{cmol}_{\mathrm{c}} \mathrm{dm}^{-3}\right)$ & 9,2 & 8,6 & 9,6 & 7,4 & 10,6 & 8,1 & 10,1 & 8,3 \\
\hline $\mathrm{V}(\%)$ & 45,0 & 7,0 & 69,0 & 61,0 & 49,0 & 14,0 & 68,0 & 62,0 \\
\hline $\mathrm{Al}^{3+}\left(\mathrm{cmol}_{\mathrm{c}} \mathrm{dm}^{-3}\right)$ & 0,3 & 1,2 & 0,0 & 0,0 & 0,2 & 0,7 & 0,0 & 0,0 \\
\hline $\mathrm{m}(\%)$ & 7,0 & 67,0 & 0,0 & 0,0 & 4,0 & 39,0 & 0,0 & 0,0 \\
\hline $\operatorname{coT}(\%)$ & 3,1 & 2,1 & 3,1 & 2,2 & 3,1 & 2,1 & 3,1 & 2,1 \\
\hline P-rem $\left(\mathrm{mg} \mathrm{L}^{-1}\right)$ & 24,5 & 7,6 & 17,8 & 12,0 & 22,4 & 16,9 & 23,3 & 20,9 \\
\hline
\end{tabular}

P-Mel = P-Mehlich-1; P-Res = P-resina; $\mathrm{SB}=$ soma de bases; $\mathrm{t}=\mathrm{CTC}$ efetiva; $\mathrm{T}=\mathrm{CTC} \mathrm{pH}$ 7,0; COT $=\mathrm{C}$ orgânico total; $\mathrm{P}$-rem $=$ P-remanescente.

moléculas de AOBMM pró-análise. Como eluente, foi utilizada solução de $\mathrm{H}_{3} \mathrm{PO}_{4} 0,1 \%$, a um fluxo de $0,5 \mathrm{~mL}$ min $^{-1}$, com injeção de $100 \mu \mathrm{L}$ de amostra. $\mathrm{O}$ tempo de aquisição dos cromatogramas foi de $35 \mathrm{~min}$, com intervalo de um minuto entre as corridas. Foi utilizado um detector de arranjo de diodos operando a $210 \mathrm{~nm}$. A temperatura durante as análises cromatográficas variou de 23 a $29^{\circ} \mathrm{C}$. As moléculas foram identificadas de acordo com o tempo de retenção dos seguintes padrões de moléculas puras, na concentração de $100 \mu \mathrm{mol} \mathrm{L}{ }^{-1}$ : ácidos oxálico, maléico, cítrico, tartático, málico, malônico, succínico, lático, fórmico, acético, ftálico e propiônico. As concentrações de cada ácido foram calculadas por meio de áreas determinadas por curvas de calibração para a respectiva molécula identificada nos lixiviados.

Por meio da concentração de cada molécula, foram determinadas a concentração de $\mathrm{C}$ e, na seqüência, a quantidade de $\mathrm{C}$ na forma de AOBMM (C-AOBMM) em cada lixiviado. Calculou-se ainda a relação $\mathrm{C}$ AOBMM/CSA, ou seja, quanto do C solúvel em água era composto por AOBMM. Foram ainda tomadas as medidas de $\mathrm{pH}$ e quantidades de $\mathrm{P}$ (Standard..., 1999) em cada lixiviado, a fim de obter possíveis relações com as variáveis de interesse principal.

Para as variáveis médias de massas molares, somatórios totais de CSA e C-AOBMM e relação CAOBMM/CSA, foi realizada a análise de variância, com as médias testadas pelo teste de Scott-Knott a $5 \%$. Foram feitas análises de correlação linear simples entre os componentes de $\mathrm{C}$ medidos nos lixiviados e os atributos químicos do solo. Quando pertinente, os componentes medidos nos lixiviados foram correlacionados entre si, sendo o grau de significância testado pelo teste de t-student.

\section{RESULTADOS E DISCUSSÃO}

Os solos estudados apresentaram comportamentos significativamente diferentes, o que foi atribuído aos seus teores de óxidos de Fe (Quadro 1). Dentre os tratamentos, a adição de $\mathrm{P}$, principalmente em conjunto com a calagem, foi o fator que mais aumentou as quantidades de CSA nos lixiviados (Quadro 3). Em geral, houve maior lixiviação de CSA no LV2. Entretanto, comparando somente os tratamentos controle (sem calagem e sem $\mathrm{P}$ ), o LV1 perdeu mais CSA que o LV2 (Quadro 3), o que está coerente com os teores de carbono orgânico total (COT) de ambos os solos (Quadro 1). Em condições de campo, PatelSorrentino et al. (2007) observaram concentrações de 0,10 a 0,16 mmol L-1 de C dissolvido em percolados de um Oxissolo amazônico não perturbado. As concentrações médias de CSA encontradas nos controles deste estudo (dados não apresentados) foram até seis vezes maiores que as encontradas no estudo de Patel-Sorrentino et al. (2007). Isso permite inferir que basta desagregar o solo (prática necessária para aplicação dos tratamentos neste estudo) para se elevar as perdas de $\mathrm{C}$ do solo por lixiviação, o que demonstra a importância da redução do revolvimento do solo para a conservação da matéria orgânica.

A aplicação de $\mathrm{P}$ foi o fator que mais influenciou a quantidade de CSA na solução lixiviada, sobretudo 
quando em conjunto com calcário, notadamente no LV2 que, apesar de conter $33 \%$ menos de COT (Quadro 1), lixiviou mais que o dobro de CSA, em relação ao LV1 no tratamento com Ca + P (Quadro 3). Isto está de acordo com os dados de Filep et al. (2003), que observaram aumento de $\mathrm{C}$ orgânico dissolvido em água de acordo com o acréscimo do $\mathrm{pH}$. Considerando a análise da distribuição das quantidades de CSA perdidas em cada lixiviado, verificou-se que, em relação ao controle, isso ocorreu somente no LV2 (Figura 1), visto que no LV1 a calagem não apresentou diferença (Quadro 3 e Figura 1), o que pode ser corroborado pela ausência de significância da correlação CSAxpH no LV1 (Quadro 4). Para esse solo, houve significância somente para correlação entre o CSA e os teores de P disponível (Mehlich-1 e Resina). Provavelmente, isto se deve ao fato de o LV1 apresentar $\mathrm{pH}$ e saturação por bases (V) naturalmente maiores (Quadro 1), resultando em menor resposta do corretivo aplicado (Quadro 2). O LV2, por apresentar valores de $\mathrm{pH} \mathrm{e} \mathrm{V}$ naturais mais baixos (Quadro 1), apresentou correlação significativa para CSAxpH, além de, ainda, ter sido verificada correlação positiva entre o CSA e os teores de P disponíveis pela resina aniônica (Quadro 4). Situação semelhante foi verificada para as quantidades de CSA lixiviadas e os valores de $\mathrm{pH}$ dos lixiviados para o LV2 $\left(\mathrm{CSAxpH}, \mathrm{r}=0,68^{\mathrm{p}<0,15}\right)$ e quantidade de $\mathrm{P}$ lixiviada para o LV1 (CSAxP, $\mathrm{r}=$ $0,95^{p<0,05}$ ) . Em geral, dentre os extratores de $\mathrm{P}, \mathrm{o}$ método da resina mostrou-se mais sensível a possíveis inferências dos efeitos da aplicação desse nutriente sobre as lixiviações de CSA, uma vez que apresentou correlações significativas para ambos os solos (Quadro 4).

Quadro 3. Quantidades acumuladas (10 coletas) de carbono na forma de ácido orgânico de baixa massa molar (C-AOBMM), carbono solúvel em água (CSA) e relação entre estas duas formas (CSA/C-AOBMM), em Latossolos Vermelhos (mesoférrico - LV1 e hipoférrico - LV2), sob efeito de calcário e, ou, fósforo

\begin{tabular}{|c|c|c|c|c|}
\hline \multicolumn{2}{|c|}{ Tratamento } & \multirow{2}{*}{$\begin{array}{l}\text { C-АОВMM } \\
\mathrm{mn}\end{array}$} & \multirow{2}{*}{$\begin{array}{c}\text { CSA } \\
\end{array}$} & \multirow{2}{*}{$\begin{array}{c}\text { C-AOBMM/CSA } \\
\%\end{array}$} \\
\hline & & & & \\
\hline \multirow[t]{4}{*}{ Latossolo mesoférrico (LV1) } & Controle & 3,02 aA & $9,32 \mathrm{cA}$ & $32,40 \mathrm{a}$ \\
\hline & Fósforo & 3,72 aA & $24,67 \mathrm{bA}$ & $15,08 \mathrm{~b}$ \\
\hline & Calcário & 3,35 aA & $9,96 \mathrm{cB}$ & 33,62 a \\
\hline & Calcário + fósforo & 3,27 aA & $37,21 \mathrm{aB}$ & $8,79 \mathrm{~b}$ \\
\hline \multirow[t]{4}{*}{ Latossolo hipoférrico (LV2) } & Controle & $1,13 \mathrm{bB}$ & $5,51 \mathrm{~dB}$ & $20,51 \mathrm{a}$ \\
\hline & Fósforo & $1,20 \mathrm{bB}$ & $27,16 \mathrm{bA}$ & $4,42 \mathrm{~b}$ \\
\hline & Calcário & $1,51 \mathrm{bB}$ & $16,13 \mathrm{cA}$ & $9,36 \mathrm{~b}$ \\
\hline & Calcário + fósforo & 3,61 aA & 82,56 aA & $4,37 \mathrm{~b}$ \\
\hline
\end{tabular}

Médias seguidas de letras iguais não diferem entre si (Scott-Knott, $\mathrm{p}<0,05)$ : minúsculas comparam tratamentos dentro de cada solo, enquanto maiúsculas comparam solos dentro de cada tratamento.
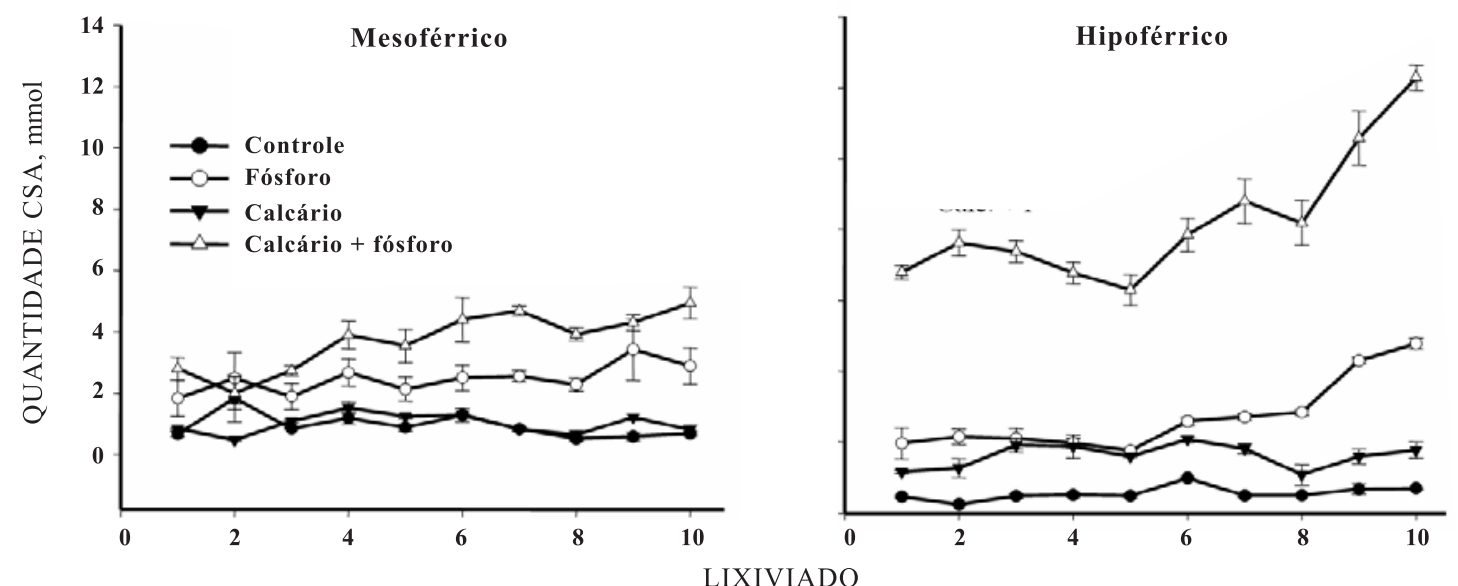

Figura 1. Distribuição das quantidades de C solúvel em água (CSA) em lixiviados de Latossolos Vermelhos (mesoférrico - LV1 e hipoférrico - LV2) tratados com calcário e, ou, fósforo. 
Quadro 4. Coeficientes de correlação linear simples $(n=4)$ entre os atributos químicos do solo e as quantidades de carbono na forma de ácidos orgânicos de baixa massa molar (C-AOBMM) e carbono solúvel em água (CSA), lixiviadas de Latossolos Vermelhos (mesoférrico - LV1 e hipoférrico - LV2)

\begin{tabular}{lcccccccccccc}
\hline \multicolumn{1}{c}{ Atributo } & $\mathbf{p H ~ H} \mathbf{O}$ & $\mathbf{P}-\mathbf{M e l}$ & $\mathbf{P}-\mathbf{R e s}$ & $\mathbf{C a}^{2+}$ & $\mathbf{M g}^{2+}$ & $\mathbf{t}$ & $\mathbf{T}$ & $\mathbf{V}$ & $\mathbf{A l}^{3+}$ & $\mathbf{m}$ & $\mathbf{C O T}$ \\
\hline CSA $-\mathrm{LV} 1$ & $0,48^{\mathrm{ns}}$ & $0,91^{* * *}$ & $0,88^{* *}$ & $0,37^{\mathrm{ns}}$ & $0,50^{\mathrm{ns}}$ & $0,71^{*}$ & $0,52^{\mathrm{ns}}$ & $0,33^{\mathrm{ns}}$ & $-0,40^{\mathrm{ns}}$ & $-0,44^{\mathrm{ns}}$ & $-0,55^{\mathrm{ns}}$ \\
$\mathrm{CSA}-\mathrm{LV} 2$ & $0,74^{*}$ & $0,66^{\mathrm{ns}}$ & $0,78^{*}$ & $0,54^{\mathrm{ns}}$ & $0,61^{\mathrm{ns}}$ & $0,15^{\mathrm{ns}}$ & $0,66^{\mathrm{ns}}$ & $0,59^{\mathrm{ns}}$ & $-0,61^{\mathrm{ns}}$ & $-0,61^{\mathrm{ns}}$ & $-0,32^{\mathrm{ns}}$ \\
$\mathrm{C}-\mathrm{AOBMM}-\mathrm{LV} 1$ & $-0,05^{\mathrm{ns}}$ & $0,64^{\mathrm{ns}}$ & $0,68^{\mathrm{ns}}$ & $0,17^{\mathrm{ns}}$ & $-0,23^{\mathrm{ns}}$ & $0,90^{* \star *}$ & $0,20^{\mathrm{ns}}$ & $0,00^{\mathrm{ns}}$ & $-0,15^{\mathrm{ns}}$ & $-0,26^{\mathrm{ns}}$ & $-0,74^{*}$ \\
C-AOBMM - LV2 & $0,73^{*}$ & $0,43^{\mathrm{ns}}$ & $0,58^{\mathrm{ns}}$ & $0,66^{\mathrm{ns}}$ & $0,72^{*}$ & $0,13^{\mathrm{ns}}$ & $0,78^{*}$ & $0,70^{*}$ & $-0,65^{\mathrm{ns}}$ & $-0,65^{\mathrm{ns}}$ & $-0,20^{\mathrm{ns}}$ \\
\hline
\end{tabular}

$\overline{* * *},{ }^{* *},{ }^{*} \mathrm{e}^{\text {ns: }}$ : Significativos a 5, 10 e 15\% e não-significativo, respectivamente (Teste t-student). P-Mel = P-Mehlich-1; P-Res = Presina; $\mathrm{t}=\mathrm{CTC}$ efetiva; $\mathrm{T}=\mathrm{CTC} \mathrm{pH}$ 7,0l; $\mathrm{COT}=$ carbono orgânico total.

Em estudos de laboratório, além do aumento do $\mathrm{pH}$, a aplicação de fosfato é um dos fatores que exercem forte influência sobre os teores de matéria orgânica dissolvida em água (Kalbitz et al., 2000). A adsorção específica de $\mathrm{P}$, por consumir cargas positivas do solo, faz com que o ponto isoelétrico do solo se torne menor que o pH (Lima et al., 2000). Além disso, a adsorção de P desloca hidroxilas da fase sólida para a solução do solo, aumentando o $\mathrm{pH}$ do sistema (Myers \& Thien, 1991), fenômeno conhecido como autocalagem. Tudo isso, aliado à aplicação de calcário, garante o predomínio de cargas líquidas negativas ao solo. Neste estudo, o predomínio de cargas de mesmo sinal certamente contribuiu, graças ao fenômeno de repulsão, para exposição/liberação da matéria orgânica protegida nos agregados. O LV2, por apresentar menor teor COT (Quadro 1), pode ter agregados menos estáveis e, conseqüentemente, maior proporção de matéria orgânica protegida fisicamente a ser liberada. Nóbrega et al. (2005) relatam o forte efeito da aplicação conjunta de calcário e fosfato sobre a dispersão da argila. Além disso, o LV2 apresentou maior CMAP (Quadro 1) e maior resposta ao calcário que o LV1, ou seja, o maior efeito de troca de ligantes (Afif et al., 1995) no LV2 pode também ter contribuído para maior perda do CSA.

Karlik (1995) verificou que, ao longo de quatro anos, a perda de C por lixiviação foi de $14,8 \mathrm{~kg} \mathrm{ha}^{-1}$ para solos corrigidos quimicamente e de $11,1 \mathrm{~kg} \mathrm{ha}^{-1}$ para aqueles não corrigidos, e que as maiores perdas de $\mathrm{C}$ foram para solos mantidos em pousio. As quantidades de CSA tiveram tendência a aumentar das primeiras lixiviações para as últimas, sobretudo para o LV2 nos tratamentos com P (Figura 1), evidenciando um efeito prolongado. Nesses tratamentos, em aproximadamente 30 dias, as perdas de $\mathrm{C}$ por lixiviação para o LV2 e para o LV1 seriam de 1,98 e 0,89 $\mathrm{kg} \mathrm{ha}^{-1}$, respectivamente. Estes números, quando comparados aos apresentados por Karlik (1995) (aproximadamente, $194 \mathrm{~kg} \mathrm{ha}^{-1}$ de C- $\mathrm{CO}_{2}$ perdidos no tratamento com correção de solo, durante 30 dias), podem parecer sem importância, mas demonstram a relevância de um manejo conservacionista do solo, com aplicação racio- nal de insumos, com reduzido revolvimento do solo, com manutenção dos restos vegetais na superfície e constante aporte de $\mathrm{C}$ ao solo.

A presença e as quantidades/concentrações de ácidos orgânicos de baixa massa molar nos lixiviados mostraram diferença ao longo do tempo (Figura $2 \mathrm{e}$ Quadro 5), comprovando sua alta labilidade em solos.

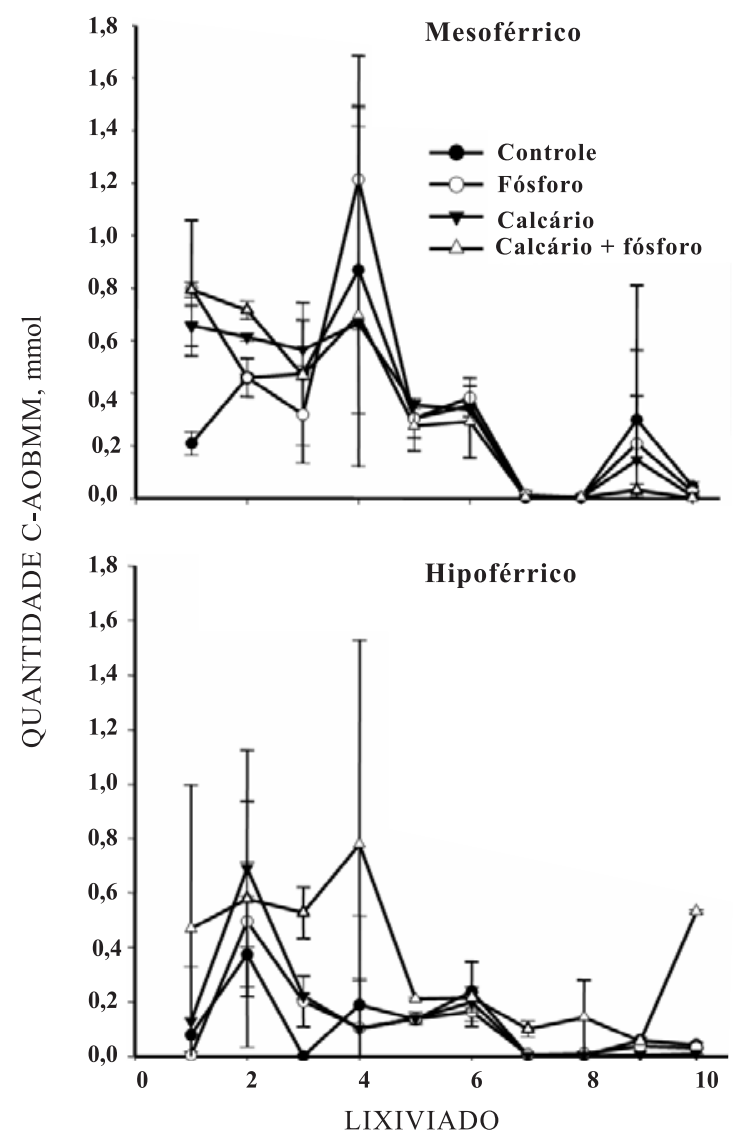

Figura 2. Distribuição das quantidades de $\mathrm{C}$ na forma de ácidos orgânicos de baixa massa molar (CAOBMM) em lixiviados Latossolos Vermelhos (mesoférrico-LV1 e hipoférrico-LV2) tratados com calcário e, ou, fósforo. 
Quadro 5. Concentrações e tipos de ácidos orgânicos de baixa massa molar em 10 lixiviados de Latossolos Vermelhos (mesoférrico - LV1 e hipoférrico - LV2) tratados com calcário e, ou, fósforo

\begin{tabular}{|c|c|c|c|c|c|c|c|c|c|c|c|}
\hline \multirow{3}{*}{\multicolumn{2}{|c|}{ Tratamento }} & \multicolumn{10}{|c|}{ Lixiviado } \\
\hline & & \multicolumn{2}{|c|}{1} & \multicolumn{2}{|l|}{2} & \multicolumn{2}{|c|}{3} & \multicolumn{2}{|l|}{4} & \multicolumn{2}{|c|}{5} \\
\hline & & Ácido & $\mu \mathrm{mol} \mathrm{L}-1$ & Ácido & $\mu \mathrm{mol} \mathrm{L}-1$ & Ácido & $\mu \mathrm{mol} \mathrm{L}^{-1}$ & Ácido & $\mu \mathrm{mol} \mathrm{L}-1$ & Ácido & $\mu \mathrm{mol} \mathrm{L}^{-1}$ \\
\hline \multirow[t]{4}{*}{$\begin{array}{l}\text { Latossolo } \\
\text { mesoférrico } \\
\text { (LV1) }\end{array}$} & Controle & $\begin{array}{l}\text { Maléico } \\
\text { Fumárico } \\
\text { Lático } \\
\text { Tartárico }\end{array}$ & $\begin{array}{r}279,4 \\
1,9 \\
83,2 \\
92,9\end{array}$ & $\begin{array}{l}\text { Maléico } \\
\text { Fumárico } \\
\text {.- } \\
\text {.- }\end{array}$ & $\begin{array}{c}581,6 \\
2,3 \\
-. \\
-\cdot\end{array}$ & $\begin{array}{c}-- \\
-- \\
\text { Cítrico } \\
--\end{array}$ & $\begin{array}{c}-- \\
-- \\
321,2 \\
--\end{array}$ & $\begin{array}{c}.- \\
\cdots \\
\cdot- \\
\text { Tartárico }\end{array}$ & $\begin{array}{c}-- \\
-- \\
-- \\
574,6\end{array}$ & $\begin{array}{c}\text { Maléico } \\
\text { Fumárico } \\
\text {.- } \\
\text {.- }\end{array}$ & $\begin{array}{c}478,8 \\
2,0 \\
-- \\
--\end{array}$ \\
\hline & Fósforo & $\begin{array}{l}\text { Maléico } \\
\text { Fumárico } \\
\text { Lático } \\
\text { Propiônico }\end{array}$ & $\begin{array}{r}809,8 \\
9,9 \\
84,3 \\
652,7\end{array}$ & $\begin{array}{l}\text { Maléico } \\
\text { Fumárico } \\
\quad-- \\
\text { Cítrico }\end{array}$ & $\begin{array}{c}557,4 \\
5,9 \\
-- \\
292,8\end{array}$ & $\begin{array}{c}-- \\
-- \\
-- \\
\text { Cítrico }\end{array}$ & $\begin{array}{c}-- \\
-- \\
-- \\
214,3\end{array}$ & $\begin{array}{c}-\cdot \\
\text { Tartárico } \\
\text {-. }\end{array}$ & $\begin{array}{c}-- \\
-- \\
806,0 \\
--\end{array}$ & $\begin{array}{l}\text { Maléico } \\
\text { Fumárico } \\
\quad-- \\
\text { Cítrico }\end{array}$ & $\begin{array}{r}454,0 \\
2,2 \\
-- \\
235,2\end{array}$ \\
\hline & Calcário & $\begin{array}{l}\text { Maléico } \\
\text { Fumárico } \\
\text {.- }\end{array}$ & $\begin{array}{c}875,8 \\
2,2 \\
.-\end{array}$ & $\begin{array}{l}\text { Maléico } \\
\text { Fumárico } \\
\text {.- }\end{array}$ & $\begin{array}{r}779,1 \\
2,7 \\
--\end{array}$ & $\begin{array}{l}\text { Cítrico } \\
\text { Fumárico } \\
\text { Tartárico }\end{array}$ & $\begin{array}{r}161,4 \\
1,2 \\
692,4\end{array}$ & $\begin{array}{c}\cdots \\
\cdots \\
\text { Tartárico }\end{array}$ & $\begin{array}{c}-- \\
-- \\
643,8\end{array}$ & $\begin{array}{l}\text { Maléico } \\
\text { Fumárico } \\
\text {.- }\end{array}$ & $\begin{array}{c}541,4 \\
2,2 \\
--\end{array}$ \\
\hline & Calc. + P & $\begin{array}{l}\text { Maléico } \\
\text { Fumárico } \\
\text {.- }\end{array}$ & $\begin{array}{c}1068,2 \\
2,2 \\
--\end{array}$ & $\begin{array}{l}\text { Maléico } \\
\text { Fumárico } \\
\text {.- }\end{array}$ & $\begin{array}{r}939,3 \\
2,5 \\
-.\end{array}$ & $\begin{array}{l}\quad-- \\
\text { Tartárico } \\
\text { Cítrico }\end{array}$ & $\begin{array}{c}-- \\
466,9 \\
275,5\end{array}$ & Tartárico & $\begin{array}{c}-- \\
706,3 \\
--\end{array}$ & $\begin{array}{l}\text { Maléico } \\
\text { Fumárico } \\
\text { Cítrico }\end{array}$ & $\begin{array}{r}403,2 \\
2,2 \\
224,8\end{array}$ \\
\hline \multirow[t]{6}{*}{$\begin{array}{l}\text { Latossolo } \\
\text { hipoférrico } \\
\text { (LV2) }\end{array}$} & Controle & $\begin{array}{l}\text { Maléico } \\
\text { Fumárico } \\
\text {.- }\end{array}$ & $\begin{array}{r}158,3 \\
4,4 \\
-\cdot\end{array}$ & $\begin{array}{l}\text { Maléico } \\
\text { Fumárico } \\
\text { Malônico }\end{array}$ & $\begin{array}{c}198,9 \\
1,9 \\
1157,7\end{array}$ & Fumárico & $\begin{array}{l}-- \\
1,2 \\
--\end{array}$ & $\begin{array}{c}\cdots \\
\cdots \\
\text { Tartárico }\end{array}$ & $\begin{array}{c}-- \\
-- \\
383,9\end{array}$ & $\begin{array}{l}\text { Maléico } \\
\text { Fumárico }\end{array}$ & $\begin{array}{r}216,2 \\
2,7\end{array}$ \\
\hline & Fósforo & Fumárico & $\begin{array}{l}- \\
2,6 \\
-\cdot\end{array}$ & $\begin{array}{l}\text { Maléico } \\
\text { Fumárico } \\
\text {-- }\end{array}$ & $\begin{array}{r}573,8 \\
1,7 \\
--\end{array}$ & $\begin{array}{l}\text { Fumárico } \\
\text { Cítrico }\end{array}$ & $\begin{array}{r}-- \\
1,2 \\
172,4\end{array}$ & $\begin{array}{c}\cdots \\
\cdots \\
\text { Tartárico }\end{array}$ & $\begin{array}{c}-- \\
-- \\
214,9\end{array}$ & $\begin{array}{l}\text { Maléico } \\
\text { Fumárico } \\
\text { Cítrico }\end{array}$ & $\begin{array}{r}179,1 \\
2,2 \\
134,7\end{array}$ \\
\hline & Calcário & $\begin{array}{l}\text { Maléico } \\
\text { Fumárico } \\
\text { Lático } \\
\text { Cítrico }\end{array}$ & $\begin{array}{r}194,8 \\
71,9 \\
85,7 \\
40,9\end{array}$ & $\begin{array}{l}\text { Maléico } \\
\text { Fumárico } \\
\quad-- \\
\text { Propiônico }\end{array}$ & $\begin{array}{c}469,7 \\
1,7 \\
-- \\
1848,6\end{array}$ & $\begin{array}{c}-- \\
-- \\
-- \\
\text { Cítrico }\end{array}$ & $\begin{array}{c}-- \\
-- \\
-- \\
126,9\end{array}$ & $\begin{array}{c}\cdots \\
\cdots \\
\cdots \\
\text { Tartárico }\end{array}$ & $\begin{array}{c}-- \\
-- \\
-- \\
224,3\end{array}$ & $\begin{array}{l}\text { Maléico } \\
\text { Fumárico } \\
\quad \text {-. } \\
\text { Cítrico }\end{array}$ & $\begin{array}{c}184,8 \\
2,4 \\
-- \\
130,8\end{array}$ \\
\hline & Calc. + P & $\begin{array}{l}\text { Maléico } \\
\text { Fumárico } \\
\text { Malônico } \\
\text { Propiônico } \\
\text { Lático }\end{array}$ & $\begin{array}{r}795,5 \\
2,9 \\
160,4 \\
580,6 \\
96,3\end{array}$ & $\begin{array}{l}\text { Maléico } \\
\text { Fumárico } \\
\text { Cítrico } \\
\text { Propiônico } \\
\text { Lático }\end{array}$ & $\begin{array}{l}490,6 \\
1,7 \\
287,6 \\
1559,2 \\
129,9\end{array}$ & $\begin{array}{c}-- \\
-- \\
\text { Cítrico } \\
-- \\
--\end{array}$ & $\begin{array}{c}-- \\
-- \\
333,6 \\
-- \\
--\end{array}$ & $\begin{array}{c}-\cdot \\
-\cdot \\
- \\
-\cdot \\
\text { Tartárico }\end{array}$ & $\begin{array}{c}-- \\
-- \\
-- \\
-- \\
793,0\end{array}$ & $\begin{array}{l}\text { Maléico } \\
\text { Fumárico } \\
\text { Cítrico } \\
\text {.- } \\
\text {.- }\end{array}$ & $\begin{array}{r}264,1 \\
2,3 \\
245,2 \\
-- \\
--\end{array}$ \\
\hline & & 6 & & 7 & & 8 & & 9 & & 10 & \\
\hline & & Ácido & $\mu \mathrm{mol} \mathrm{L}-1$ & Ácido & $\mu \mathrm{mol} \mathrm{L}-1$ & Ácido & $\mu \mathrm{mol} \mathrm{L}^{-1}$ & Ácido & $\mu \mathrm{mol} \mathrm{L}^{-1}$ & Ácido & $\mu_{\mathrm{mol} \mathrm{L}}^{-1}$ \\
\hline \multirow[t]{4}{*}{$\begin{array}{l}\text { Latossolo } \\
\text { mesoférrico } \\
\text { (LV1) }\end{array}$} & Controle & $\begin{array}{l}\text { Maléico } \\
\text { Fumárico } \\
\text {-- }\end{array}$ & $\begin{array}{c}477,3 \\
2,4 \\
\quad \cdot\end{array}$ & $\begin{array}{c}\text { Fumárico } \\
\text {-- }\end{array}$ & $\begin{array}{l}- \\
2,3 \\
--\end{array}$ & Fumárico & $\begin{array}{l}-- \\
2,4 \\
--\end{array}$ & $\begin{array}{l}\text { Maléico } \\
\text { Fumárico } \\
\text {.- }\end{array}$ & $\begin{array}{c}618,2 \\
1,6 \\
--\end{array}$ & $\begin{array}{l}\text { Maléico } \\
\text { Fumárico } \\
\text { Cítrico }\end{array}$ & $\begin{array}{r}29,0 \\
1,5 \\
51,8\end{array}$ \\
\hline & Fósforo & $\begin{array}{l}\text { Maléico } \\
\text { Fumárico } \\
\text {-- }\end{array}$ & $\begin{array}{c}514,2 \\
2,3 \\
-\cdot\end{array}$ & Fumárico & $\begin{array}{l}-\cdot \\
8,4 \\
-\cdot\end{array}$ & Fumárico & $\begin{array}{l}-- \\
2,6 \\
--\end{array}$ & $\begin{array}{l}\text { Fumárico } \\
\text { Propiônico }\end{array}$ & $\begin{array}{r}-- \\
1,8 \\
833,4\end{array}$ & $\begin{array}{l}\text { Maléico } \\
\text { Fumárico } \\
\text {.- }\end{array}$ & $\begin{array}{r}29,2 \\
2,5 \\
--\end{array}$ \\
\hline & Calcário & $\begin{array}{l}\text { Maléico } \\
\text { Fumárico }\end{array}$ & $\begin{array}{r}455,1 \\
2,2\end{array}$ & Fumárico & $\begin{array}{l}-\cdot \\
2,3\end{array}$ & Fumárico & $\begin{array}{l}-- \\
2,6\end{array}$ & Fumárico & $\begin{array}{r}-- \\
145,5\end{array}$ & $\begin{array}{l}\text { Maléico } \\
\text { Fumárico }\end{array}$ & $\begin{array}{l}8,5 \\
2,5\end{array}$ \\
\hline & Calc. + P & $\begin{array}{l}\text { Maléico } \\
\text { Fumárico } \\
\text { Cítrico }\end{array}$ & $\begin{array}{r}355,6 \\
2,2 \\
212,8\end{array}$ & Fumárico & $\begin{array}{l}-\cdot \\
2,3 \\
--\end{array}$ & Fumárico & $\begin{array}{l}-- \\
2,4 \\
--\end{array}$ & $\begin{array}{l}\text { Maléico } \\
\text { Fumárico } \\
\text {.- }\end{array}$ & $\begin{array}{c}57,7 \\
2,1 \\
--\end{array}$ & Fumárico & $\begin{array}{l}-- \\
1,6 \\
--\end{array}$ \\
\hline \multirow[t]{4}{*}{$\begin{array}{l}\text { Latossolo } \\
\text { hipoférrico } \\
\text { (LV2) }\end{array}$} & Controle & $\begin{array}{l}\text { Maléico } \\
\text { Fumárico } \\
\text {-- }\end{array}$ & $\begin{array}{r}192,2 \\
2,4 \\
\quad-\end{array}$ & Fumárico & $\begin{array}{l}-- \\
2,6 \\
--\end{array}$ & Fumárico & $\begin{array}{l}-- \\
2,5 \\
--\end{array}$ & $\begin{array}{l}\text { Maléico } \\
\text { Fumárico } \\
\text { Cítrico }\end{array}$ & $\begin{array}{r}66,2 \\
3,0 \\
38,9\end{array}$ & $\begin{array}{l}\text { Maléico } \\
\text { Fumárico } \\
\text { Cítrico }\end{array}$ & $\begin{array}{r}48,4 \\
2,3 \\
35,7\end{array}$ \\
\hline & Fósforo & $\begin{array}{l}\text { Maléico } \\
\text { Fumárico } \\
\text { Cítrico }\end{array}$ & $\begin{array}{r}207,1 \\
2,4 \\
114,6\end{array}$ & $\begin{array}{l}\text { Maléico } \\
\text { Fumárico } \\
\text {.- }\end{array}$ & $\begin{array}{c}16,2 \\
2,6 \\
--\end{array}$ & $\begin{array}{l}\text { Maléico } \\
\text { Fumárico } \\
\text {-- }\end{array}$ & $\begin{array}{r}19,1 \\
2,0 \\
--\end{array}$ & $\begin{array}{l}\text { Maléico } \\
\text { Fumárico } \\
\text {.. }\end{array}$ & $\begin{array}{r}32,1 \\
2,2 \\
--\end{array}$ & $\begin{array}{l}\text { Maléico } \\
\text { Fumárico } \\
\text { Cítrico }\end{array}$ & $\begin{array}{r}40,7 \\
2,7 \\
18,2\end{array}$ \\
\hline & Calcário & $\begin{array}{l}\text { Maléico } \\
\text { Fumárico }\end{array}$ & $\begin{array}{r}264,0 \\
2,1\end{array}$ & Fumárico & $\begin{array}{l}-\cdot \\
2,4\end{array}$ & Fumárico & $\begin{array}{l}-- \\
2,8\end{array}$ & $\begin{array}{l}\text { Maléico } \\
\text { Fumárico }\end{array}$ & $\begin{array}{l}9,9 \\
2,4\end{array}$ & $\begin{array}{l}\text { Maléico } \\
\text { Fumárico }\end{array}$ & $\begin{array}{r}11,8 \\
2,7\end{array}$ \\
\hline & Calc. + P & $\begin{array}{l}\text { Maléico } \\
\text { Fumárico } \\
\text { Cítrico } \\
\text { Propiônico }\end{array}$ & $\begin{array}{r}223,7 \\
14,5 \\
215,7 \\
172,0\end{array}$ & $\begin{array}{c}\text { Maléico } \\
\text { Fumárico } \\
\text {.- } \\
\text {.- }\end{array}$ & $\begin{array}{c}137,8 \\
2,2 \\
-. \\
.-\end{array}$ & $\begin{array}{l}\text { Maléico } \\
\text { Fumárico } \\
-- \\
\text {-- }\end{array}$ & $\begin{array}{c}133,6 \\
2,3 \\
-- \\
--\end{array}$ & $\begin{array}{c}\text { Maléico } \\
\text { Fumárico } \\
\text {.- } \\
\text {.- }\end{array}$ & $\begin{array}{c}67,2 \\
1,8 \\
-- \\
--\end{array}$ & $\begin{array}{c}\text { Maléico } \\
\text {-. } \\
\text {-- } \\
\text {-. }\end{array}$ & $\begin{array}{c}347,1 \\
-- \\
-- \\
--\end{array}$ \\
\hline
\end{tabular}


As quantidades de C-AOBMM não diferiram estatisticamente entre os tratamentos, à exceção do tratamento $\mathrm{Ca}+\mathrm{P}$ no LV2 que, apesar de ser maior (Quadro 3), praticamente não apresentou diferença entre as lixiviações (Figura 2). Apesar das maiores quantidades de C-AOBMM lixiviadas, este foi o tratamento que apresentou maiores quantidades de CSA lixiviadas, propiciando uma das menores relações C-AOBMM/CSA (Quadro 3). Nesse caso pode-se inferir que a maior contribuição para o $\mathrm{C}$ lixiviado ficou a cargo de moléculas orgânicas maiores que os AOBMM, como, por exemplo, ácidos fúlvicos, muito embora van Hees et al. (2005) afirmem que as moléculas de baixa massa são potencialmente mais susceptíveis à lixiviação que as de alta massa molar. Como tanto a correção do pH (Karlik, 1995) como o aumento dos teores de P disponível (Myers \& Thien, 1991) aumentam a atividade microbiana e como os AOBMM são moléculas facilmente oxidáveis (van Hees et al., 2005), seu uso como substrato para microrganismos provavelmente foi preferencial, diminuindo suas quantidades nos lixiviados com maiores valores de $\mathrm{pH}$ e teores de $\mathrm{P}$.

Segundo van Hees et al. (2005), a solução do solo pode conter várias moléculas orgânicas de baixa massa molar, tais como ácidos orgânicos alifáticos, cujas concentrações podem variar de $0,1-50 \mu \mathrm{mol} \mathrm{L}^{-1}$ para AOBMM di/trivalentes (ex., ácidos cítrico e málico) e de $<1-1.000 \mu \mathrm{mol} \mathrm{L}^{-1}$ para monovalentes (p.ex., fórmico, acético e lático). As concentrações médias gerais, contudo, não seguiram a mesma ordem que a observada para a freqüência de deteç̧ão (Quadro 5). Desse modo, as concentrações médias decresceram na seguinte ordem, em $\mu \mathrm{mol} \mathrm{L}^{-1}$ : propiônico $(941,1)>$ malônico $(659,1)>$ tartárico $(559,9)>$ maléico $(327,4)$ $>$ cítrico $(176,6)>$ lático $(95,6)>$ fumárico $(5,9)$. Já a freqüência de detecção decresceu na seguinte ordem: fumárico $>$ maléico $>$ cítrico $>$ tartárico $>$ propiônico $>$ lático > malônico, com destaque para os dois primeiros que, à exceção dos lixiviados três e quatro, foram detectados em todos os lixiviados (Quadro 5). Tal fato mostra que a presença da molécula na solução do solo nem sempre significa alta concentração no lixiviado, podendo, em alguns casos, ocorrer justamente o contrário.

Os tratamentos com aplicação simultânea de calcário e P causaram o aparecimento de moléculas com maiores massas molares nos lixiviados (Quadro 6). Nesses tratamentos, ao longo do tempo, o aumento nas perdas de CSA por lixiviação foi acompanhado por um acréscimo nas massas molares dos compostos orgânicos presentes (Figura 3). Segundo Kalbitz et al. (2000), a presença de ânions na solução do solo, como o fosfato, afeta a adsorção de moléculas solúveis de $\mathrm{C}$, deslocando-as dos sítios de adsorção para a solução do solo, o que favorece as perdas de $\mathrm{C}$ por lixiviação. Apesar de compostos com maiores massas molares terem sido observados nos tratamentos com $\mathrm{Ca}+\mathrm{P}$ (Quadro 6), somente após a quinta (LV2) e a sétima (LV1) lixiviação é que foram detectados compostos orgânicos com massa molar acima de 300 daltons, cujos valores praticamente estabilizaramse até à última lixiviação (Figura 3). Foram também

Quadro 6. Médias e amplitudes das massas molares (daltons) dos compostos orgânicos em dez lixiviados de Latossolos Vermelhos (mesoférrico - LV1 e hipoférrico - LV2) tratados com calcário e, ou fósforo

Tratamento Massa molar Amplitude

\begin{tabular}{lllc}
\hline & & \multicolumn{2}{c}{ Daltons } \\
\cline { 3 - 4 } Latossolo & Controle & $313 \mathrm{bA}$ & $302-317$ \\
mesoférrico & Fósforo & $313 \mathrm{bB}$ & $303-326$ \\
(LV1) & Calcário & $314 \mathrm{bA}$ & $304-318$ \\
& Calc. + P & $466 \mathrm{aB}$ & $303-1082$ \\
Latossolo & Controle & $313 \mathrm{cA}$ & $231-317$ \\
hipoférrico & Fósforo & $375 \mathrm{bA}$ & $282-906$ \\
(LV2) & Calcário & $313 \mathrm{cB}$ & $294-317$ \\
& Calc. + P & $538 \mathrm{aA}$ & $302-1028$ \\
\hline
\end{tabular}

Médias seguidas de letras iguais não diferem entre si (ScottKnott, $\mathrm{p}<0,05)$ : letras minúsculas comparam tratamentos dentro de cada solo, enquanto maiúsculas comparam solos dentro de cada tratamento.

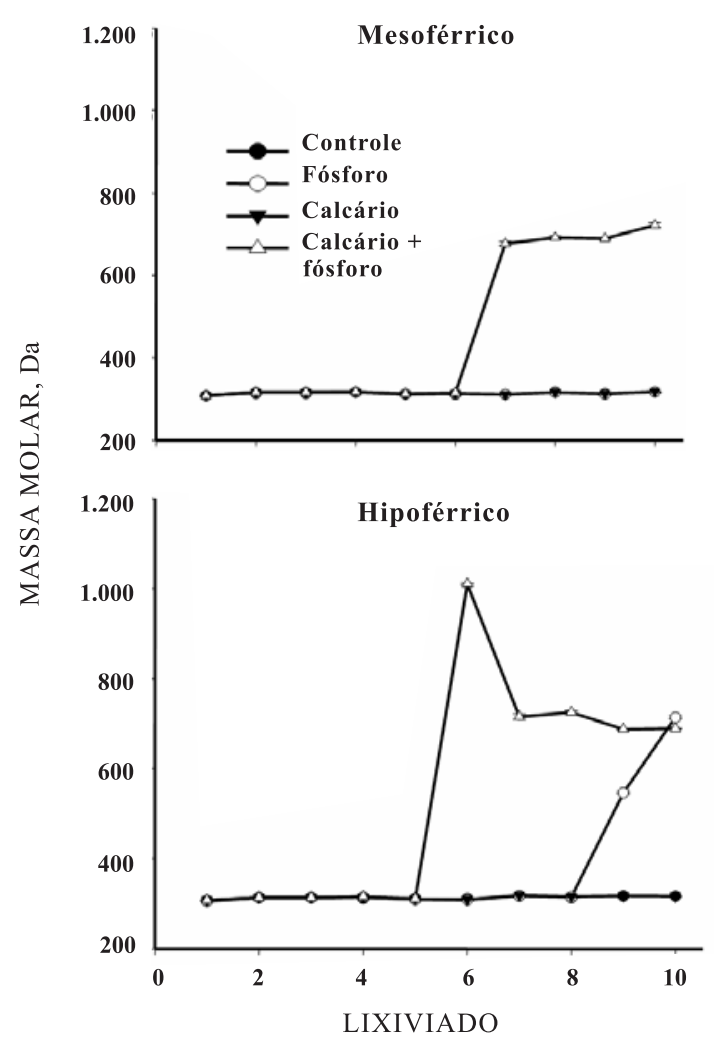

Figura 3. Distribuição de massas molares médias (daltons, Da) de compostos orgânicos em lixiviados de Latossolos Vermelhos (mesoférrico - LV1 e hipoférrico - LV2) tratados com calcário e, ou, fósforo. 
verificadas moléculas com massa molar acima de 1.000 daltons (Quadro 6), ou seja, de mesma massa que os ácidos fúlvicos (Chin \& Gschwend, 1991), demonstrando que parte do $\mathrm{C}$ nos lixiviados pertence a esse grupo de moléculas. Marschner \& Wilczynsky (1991) observaram que a aplicação de calcário em solos sob floresta resultou na conversão de ácidos húmicos a ácidos fúlvicos, que podem ser perdidos com facilidade do sistema solo-planta, graças à sua maior mobilidade, que é atribuída ao menor tamanho das moléculas (em relação aos ácidos húmicos), maior quantidade de radicais carboxílicos e maior solubilidade em $\mathrm{pH}$ elevado (Marschner \& Wilczynsky, 1991). Karlik (1995) observou aumento de 45,4\% em compostos ricos em grupamentos carboxílicos em solos tratados com carbonato de $\mathrm{Ca}$.

Neste estudo, a produção de ácidos fúlvicos (moléculas com massa molar acima de 1.000 daltons) só foi notada com a aplicação conjunta de calcário e P. Portanto, este tratamento caracterizou-se pela capacidade de promover a liberação de moléculas de maior massa molar.

\section{CONCLUSÕES}

1. As quantidades de carbono perdidas em lixiviados dos Latossolos Vermelhos aumentaram na seguinte ordem: controle $\leq$ calcário $<\mathrm{P}<\mathrm{Ca}+\mathrm{P}$; à exceção do tratamento-controle, as maiores perdas de $\mathrm{C}$ foram verificadas no Latossolo Vermelho hipoférrico.

2. Em geral, o Latossolo Vermelho mesoférrico perdeu mais $\mathrm{C}$ na forma de ácidos orgânicos de baixa massa molar.

3. A presença de um tipo específico de ácido orgânico não é indicativa de alta concentração dessa molécula no lixiviado; a freqüência de detecção de ácidos orgânicos nos lixiviados decresceu na seguinte ordem: fumárico $>$ maléico $>$ cítrico $>$ tartárico $>$ propiônico $>$ lático > malônico, ao passo que suas concentrações médias gerais seguiram a seguinte ordem: propiônico $>$ malônico $>$ tartárico $>$ maléico $>$ cítrico $>$ lático $>$ fumárico.

4. A adição de P no Latossolo Vermelho hipoférrico e o uso de $\mathrm{Ca}+\mathrm{P}$ nos dois Latossolos estudados resultaram em aumento da massa molar média das moléculas de $\mathrm{C}$ nos lixiviados coletados no final do estudo e em perda de moléculas de ácidos fúlvicos nos tratamentos com $\mathrm{Ca}+\mathrm{P}$.

\section{AGRADECIMENTOS}

Os autores agradecem à CAPES, pela cessão de bolsa de estudos ao primeiro autor, e à FAPEMIG, pelo financiamento do projeto de pesquisa.

\section{LITERATURA CITADA}

AFIF, E.; BARRON, V. \& TORRENT J. Organic matter delays but does not prevent phosphate sorption by Cerrado soils from Brazil. Soil Sci., 159:207-211, 1995.

ALVAREZ V., V.H.; NOVAIS, R.F.; DIAS, L.E. \& OLIVEIRA, J.A. Determinação e uso do fósforo remanescente. B. Inf. SBCS., 25:27-32, 2000.

ANDERSSON, S. Influence of liming substances and temperature on microbial activity and leaching of soil organic matter in coniferous forest ecosystems. Acta Univ. Agric. Suec., 116:1-68, 1999.

ANDRADE, F.V.; MENDONÇA, E.S.; ALVAREZ V., V.H. \& NOVAIS, R.F. Adição de ácidos orgânicos e húmicos em Latossolos e adsorção de fosfato. R. Bras. Ci. Solo, 27:10031011, 2003.

AZEVEDO, E.C.; FONTES, L.E.F.; COSTA, L.M. \& SILVA, J.G.M. Carbono orgânico solúvel no deflúvio de microbacias hidrográficas cobertas com mata nativa, pastagem e Eucaliptus grandis. R. Ceres, 43:755-767, 1996.

CHANTIGNY, M.H. Dissolved and water-extractable organic matter in soils: A review on the influence of land use and management practices. Geoderma, 113:357-380, 2003.

CHIN, YU-PING \& GSCHWEND, P.M. The abundance, distribution, and configuration of porewater organic colloids in recent sediments. Geochim. Cosmochim. Acta, 55:1309-1317, 1991.

CURI, N.; CHAGAS, C.S. \& GIAROLA, N.F.B. Distinção de ambientes agrícolas e relação solo-pastagens nos campos da Mantiqueira. In: CARVALHO, M.M.; EVANGELISTA, A.R. \& CURI, N. Desenvolvimento de pastagens na zona fisiográfica Campos das Vertentes-MG. Coronel Pacheco, Embrapa Gado de Leite, 1994. 127p.

DAWSON, H.J.; UGOLINI, F.C.; HRUTFIORD, B.F. \& ZACHARA, J. Role of soluble organic in the soil process of a Podzol., Central Cascades. Soil Sci., 126:290-296, 1978.

EMPRESA BRASILEIRA DE PESQUISA AGROPECUÁRIA EMBRAPA. Centro Nacional de Pesquisa de Solos. Manual de métodos de análises de solo. 2.ed. Rio de Janeiro, 1997. 212p.

ERICH, M.S. \& TRUSTY, G.M. Chemical characterization of dissolved organic matter released by limed and unlimed forest soil horizons. Can. J. Soil Sci., 77:405-413, 1997.

FILEP, T.; KINCSES, I. \& NAGY, P.T. Dissolved organic carbon (DOC) and dissolved organic nitrogen (DON) content of an arenosol as affected by liming in a pot experiment. Arch. Agr. Soil Sci., 49:111-117, 2003.

FOX, T.R. \& COMERFORD, N.B. Low-molecular-weight organic acids in selected forest soils of Southeastern USA. Soil Sci. Soc. Am. J., 54:1139-1144, 1990.

GOLCHIN, A.; OADES, J.M.; SKJEMSTAD, J.O. \& CLARKE, P. Soil-structure and carbon cycling. Aust. J. Soil Res., 32:1043-1068, 1994. 
GUGGENBERGER, G.; ZECH, W. \& SCHULTEN, H.R. Formation and mobilization pathways of dissolved organic matter: Evidence from chemical structural studies of organic matter fractions in acid forest floor solutions. Organic Geochem., 21:51-56, 1994.

HERBERT, B.E. \& BERTSCH, P.M. Characterization of dissolved and colloidal organic matter in soil solution. In: KELLY, J.M. \& MCFEE, W.W. Carbon forms and functions in forest soils. Madison, Soil Science Society of America, 1995. 63-88.

KALBITZ, K.; SOLINGER, S.; PARK, J.H.; MICHALZIK, B. \& MATZNER, E. Controls on the dynamics of dissolved organic matter in soils: A review. Soil Sci., 165:277-304, 2000 .

KARLIK, B. Liming effect on dissolved organic matter leaching. Water, Air Soil Poll., 85:949-954, 1995.

LIMA, J.M.; ANDERSON, S.J. \& CURI, N. Phosphate-induced clay dispersion as related to aggregate size and composition in Hapludoxs. Soil Sci. Soc. Am. J., 64:892-897, 2000

MARSCHNER, B. \& WILCZYNSKI, W. The effect of liming on quality and chemical composition of soil organic matter in a pine forest in Berlin, Germany. Plant Soil, 137:229236,1991

MENDONÇA, E.S. \& MATOS, E.S. Carbono solúvel em água. In: MENDONÇA, E.S. \& MATOS, E.S. Matéria orgânica: Métodos de análises. Viçosa, MG, Universidade Federal de Viçosa, 2005. p.24-27.

MIRANDA, J.; LIOVANDO, M.C.; RUIZ, H.A. \& EINLOFT, R. Composição química da solução de solo sob diferentes coberturas vegetais e análise de carbono orgânico solúvel no deflúvio de pequenos cursos de água. R. Bras. Ci. Solo, 30:633-647, 2006.

MIYAZAWA, M. \& PAVAN, M.A. Determinação de alumínio em soluções puras contendo ácidos orgânicos e em solo com eletrodo seletivo de fluoreto. Quimica Nova, 15:286290, 1992

MYERS, R. \& THIEN, S.J. Soil permeability in an ammonium and phosphorus application zone. Soil Sci. Soc. Am. J., 55:866-871, 1991.
NÓBREGA, J.C.A.; LIMA, J.M.; GUERREIRO, M.C.; RIGITANO, R.L.O. \& MORENO, S.A.C. Retenção do fungicida triadimenol em Latossolos em razão da calagem e da fosfatagem. Pesq. Agropec. Bras., 40:503-511, 2005.

PATEL-SORRENTINO, N.; LUCAS, Y.; EYROLLE, F. \& MELFI, A.J. $\mathrm{Fe}, \mathrm{Al}$ and $\mathrm{Si}$ species and organic matter leached off a ferrallitic and Podzolic soil system from Central Amazonia. Geoderma, 137:444-454, 2007.

RAULUND-RASMUSSEN， K.; BORRGGAARD， O.K.; HANSEN, H.C.B. \& OLSSON, M. Effect of natural soil solutes on weathering rates of soil minerals. Eur. J. Soil Sci., 49:397-406, 1998.

ROTH, C.M. \& PAVAN, M.A. Effects of lime and gypsum on clay dispersion and infiltration in samples of a Brazilian Oxisol. Geoderma, 48:351-361, 1991.

SILVA, C.A.; ANDERSON, S.J. \& GUILHERME, L.R.G. Uso da cromatografia de exclusão por tamanho na caracterização de substâncias húmicas de Latossolo Vermelho-Escuro sob efeito de calagem. R. Bras. Ci. Solo, 24:495-503, 2000.

STANDARD methods for the examination of water and wastewater. 4500-PE. Ascorbic Acid Method. Am. Pub. Health Ass., American Water Works Association, Water Environment Federation. Disponível em $<$ http/l :www.umass.edu/tei/mwwp/acrobat/sm4500P-E.PDF> acessado em 15 de nov. de 2005.

STEVENSON, F.J. Humus chemistry: Genesis, composition, reactions. New York, John Wiley \& Sons, 1994. 496p.

van HEES, P.A.W.; DAHLÉN. J.; LUNDSTRÖM, U.S.; BORÉN, H. \& ALLARD, B. Determination of low molecular weight organic acids in soil solution by HPLC. Talanta, 48:173179,1999

van HESS, P.A.W.; JONES D.L.; FINLAY, R.; GODBOLD, D.L. \& LUNDSTRÖN, U.S. The carbon we do not see - the impact of low molecular weight compounds on carbon dynamics and respiration in forest soils: A review. Soil Biol. Biochem., 37:1-13, 2005.

YEOMANS, J.C. \& BREMNER, J.M. A rapid and precise method for routine determination of organic carbon in soil. Comm. Soil Sci. Plant Anal., 19:1467-1476, 1988. 